\title{
Surgical Outcome of a Challenging Big Angle Squint in a Child
}

Théra JP ${ }^{1 *}$, Tiama JM ${ }^{1}$, Konipo A ${ }^{1}$, Dakouo P, Tinley $\mathrm{C}^{2}$

${ }^{1}$ Institute of African Tropical Ophthalmology, Bamako Mali

${ }^{2}$ Pediatric Ophthalmologist, Consultant CCBRT Hospital, Dar Es Salam Tanzania

DOI: $10.36347 /$ sasjs.2020.v06i03.009

| Received: 18.02.2020 | Accepted: 25.02.2020 | Published: 18.03.2020

*Corresponding author: Dr. Japhet Pobanou Thera

\section{Abstract}

Esotropia is a deviation of the eyes inward. It is the most frequent type of strabismus. The deviation may be unilateral or bilateral. It is a leading cause of amblyopia particularly in the unilateral form. The surgical management can require a single or many procedures.

Keywords: Surgical outcome, big angle, squints.

Copyright @ 2020: This is an open-access article distributed under the terms of the Creative Commons Attribution license which permits unrestricted use, distribution, and reproduction in any medium for non-commercial use (NonCommercial, or CC-BY-NC) provided the original author and source are credited.

\section{INTRODUCTION}

Congenital or infantile esotropia is a convergent nonaccommodative persistent ocular deviation of relatively large angle which develops at approximately 6 months of age $[1,2]$.

Management of strabismus includes correction of refractive errors, management of any co-existing amblyopia, and surgery of one or more extra ocular muscles to re-align the eyes. The benefits of surgical correction include elimination of diplopia, restoration of binocular single vision, and improvement of cosmesis and psychosocial status [3]. In the current case the great concern of the mother was the improvement of cosmesis.

\section{CASE REPORT}

A 17-month-old female child brought by her mother for deviation of the left eye since birth. She was the $4^{\text {th }}$ child of 5 siblings all healthy according to her mother. She was a premature baby, born after 34 weeks of pregnancy and underwent oxygen therapy. Findings on ocular examination were: obvious esotropia of the left eye. Head turn, cross fixation and nystagmus of the deviated eye. Ocular motility was normal both eyes. The angle measured by the orthoptist was 75 Prism Diopter (PD). We performed a recession of the medial rectus and a resection of the lateral rectus in the left eye which became orthophoric and remained so after 1 year follow up.

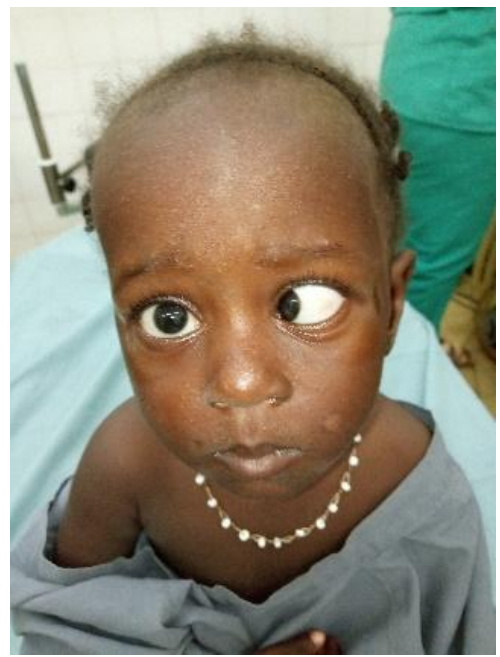

Fig-1: Photograph of the child with left eye esotropia

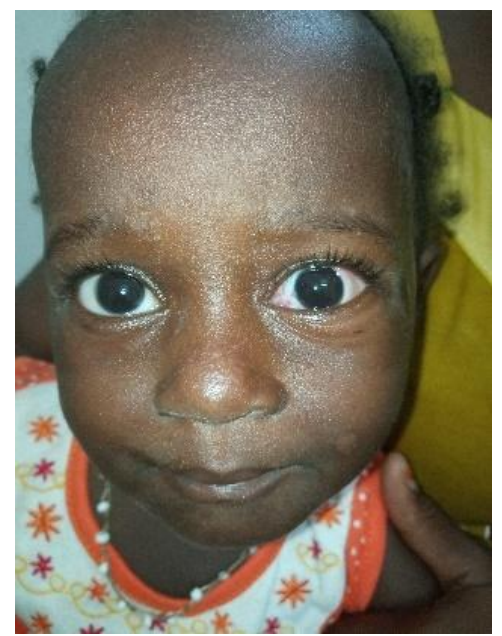

Fig-2: One year after surgery before surgery 


\section{DISCUSSION}

Squint surgery may require more than one operation. If the patients or their parents are not fully aware of this matter, the procedure may end up with disappointment. That is why it is very important to obtain the informed consent of the patient or his relatives before the procedure.

The aim of surgery in squint is mainly physiological that is restoration of binocular vision. The surgical correction of the deviation is the most important step in that direction. This anatomical correction aims at obtaining parallelism and a symmetrical appearance of the eyes in all directions of gaze [4].

There are several treatments for strabismus. Conservative options include prisms and orthoptic exercises; invasive treatments include surgery and botulinum toxin [5].

The surgery of strabismus in children is sometimes very tough. In one hand these young patients have to be operated under general anesthesia with a potential risk of cardiac arrest. In the other hand there is both a cosmetic and optical issue; because parents expect a good alignment of the eyes with good vision as well.

Residual esotropia is a common problem following bilateral medial rectus recession for esotropia that frustrates either surgeons or patients. Various studies have reported an incidence of $40 \%$ for this condition [6]. In the case presented here, instead of performing bilateral medial rectus recession, we rather performed the unilateral procedure. We performed a recession of the medial rectus and a resection of the lateral rectus in the left eye.

Bilateral recession of medial rectus muscle for large angle infantile esotropia ( $\geq 60$ PD) has been described by some investigators but the literature has reported variable success between 60 and 90\% [7]. Sometimes we ca experience recurrences after squint surgery. In our patient, we found no residual angle after one year follow up.

\section{CONCLUSION}

Squint is a disturbing medical condition. If not managed early and effectively, it may impede the patients' life. If the surgical route in chosen, the informed consent the patient or his relatives must be obtained because of the possible recurrences and residual angles.

\section{REFERENCES}

1. Age (Louwagie CR, Diehl NN, Greenberg AE, Mohney BG; Longterm follow-up of congenital esotropia in a population-based cohort. J AAPOS. 2009;13(1):8-12.

2. Botulinum toxin for strabismus correction. Débora Mayumi Sugano1, Celso Lopez Fernandez2, José Ricardo Carvalho de Lima Rehder3 Rev Bras Oftalmol. 2013; 72 (5): 321-5.

3. Hegde V, Bappal A, Puthran N. Surgical outcomes following ocular re-alignment in various types of squints. Arch Med Health Sci. 2013; 1:24-8.

4. Srinivasa Rao PN. Factors influencing the result of strabismus surgery. Indian J Ophthalmol, 1965;13:105-8.

5. Sugano DM, Fernandez CL, Rehder JRCL. Botulinum toxin for strabismus correctionRev Bras Oftalmol. 2013; 72 (5): 321-5.

6. Stager DR, Weakley DR Jr, Everett M, Birch EE; Delayed consecutive exotropia following 7milimeter bilateral medial rectus recession for congenital esotropia. J Pediatr Ophthalmol Strabismus. 1994;31(3):147-50.

7. Castro PD, Pedroso A, Hernández L, Naranjo RM, Méndez TJ, Arias A; Results of surgery for congenital esotropia. MEDICC Rev. 2011; 13(1):18-22. 